\title{
Dual antibiotherapy of tuberculosis mediated by inhalable locust bean gum
} microparticles

3 Susana Rodrigues ${ }^{1,2 \S}$, Ana D Alves ${ }^{1 \S}$, Joana S Cavaco ${ }^{1}$, Jorge F Pontes ${ }^{1,2}$, Filipa

4 Guerreiro $^{1,2}$, Ana M Rosa da $\operatorname{Costa}^{3}$, Francesca Buttini ${ }^{4}$ and Ana Grenha ${ }^{1,2^{*}}$

5

$6{ }^{1}$ Center for Biomedical Research (CBMR), Faculty of Sciences and Technology,

7 University of Algarve, Faro, Portugal; ${ }^{2}$ Centre for Marine Sciences (CCMar),

8 Faculty of Sciences and Technology, University of Algarve, Faro, Portugal;

$9 \quad{ }^{3}$ Algarve Chemistry Research Center (CIQA) and Department of Chemistry and 10 Pharmacy, Faculty of Sciences and Technology, University of Algarve, Faro, 11 Portugal; ${ }^{4}$ Department of Food and Drug Science, University of Parma, Parma, 12 Italy; §Authors with equal contribution

*Corresponding author:

15 University of Algarve

16 CBMR and CCMAR, Faculty of Sciences and Technology

17 Campus de Gambelas

18 8005-139 Faro, Portugal

19 Tel.: $+351289800100-$ Ext. 7441

$20 \quad$ Fax: +351289818419

21 E-mail address: amgrenha@ualg.pt 


\section{Abstract}

Despite the existence of effective oral therapy, tuberculosis remains a deadly pathology, namely because of bacterial resistance and incompliance with treatments. Establishing alternative therapeutic approaches is urgent and inhalable therapy has a great potential in this regard. As pathogenic bacteria are hosted by alveolar macrophages, the co-localisation of antitubercular drugs and pathogens is thus potentiated by this strategy. This work proposes inhalable therapy of pulmonary tuberculosis mediated by a single locust bean gum (LBG) formulation of microparticles associating both isoniazid and rifabutin, complying with requisites of the World Health Organisation of combined therapy. Microparticles were produced by spray-drying, at LBG/INH/RFB mass ratio of 10/1/0.5. The aerodynamic characterisation of microparticles revealed emitted doses of more than $90 \%$ and fine particle fraction of $38 \%$, thus indicating the adequacy of the system to reach the respiratory lung area, thus partially the alveolar region. Cytotoxicity results indicate moderate toxicity (cell viability around $60 \%$ ), with a concentration-dependent effect. Additionally, rat alveolar macrophages evidenced preferential capture of LBG microparticles, possibly due to chemical composition comprising mannose and galactose units that are specifically recognised by macrophage surface receptors.

Keywords: inhalation, locust bean gum, microparticles, polysaccharides, spraydrying, tuberculosis therapy 


\section{Introduction}

Tuberculosis (TB) remains a leading cause of death, with particular incidence and prevalence in developing countries (WHO, 2016 ). Drug resistance is a major problem, but therapeutic incompliance is also a great limitation (McBryde et al., 2017). Albeit the commercial availability of several effective oral and parenteral drugs and the existence of international treatment guidelines (NICE, 2016; Wells et al., 2009), new therapeutic approaches are demanded not only to improve compliance but also to reduce the severe side effects associated with conventional therapy (Kaur et al., 2016; Lee et al., 2015). Inhalable therapy has great potential in this context, enabling the direct administration of drugs to the alveoli, where macrophages hosting pathogenic bacteria are located (Gupta et al., 2016; Parumasivam et al., 2016).

In a previous work, we proposed the use of spray-dried microparticles based on locust bean gum (LBG) as inhalable formulation for the treatment of pulmonary tuberculosis. The individual association of first-line antitubercular drugs was effective and a preliminary assay further suggested high affinity of LBG microparticles for macrophages (Alves et al., 2016), which we explained by specific recognition of the mannose and galactose residues of microparticles by macrophage surface receptors (Ahsan et al., 2002). LBG was proposed in that work for the first time for lung delivery applications. It is a galactomannan and its biodegradability has been ascribed to the presence of $\beta$-mannosidase in the lung (Alkhayat et al., 1998).

This work intends to produce a dry powder that delivers two antitubercular drugs upon inhalation while providing improved internalisation by macrophages, mediated by LBG. Furthermore, the respirability of LBG microparticles was 
studied in order to determine their inhalability when used as carriers for antitubercular drugs. The microparticle aerosolisation profile was experimentally determined. The uptake by macrophages was assessed and compared with that of microparticles composed by a polymer devoid of specific moieties recognizable by macrophage receptors. Finally, combined therapy is proposed by the association of two first-line antitubercular drugs (isoniazid and rifabutin) in a single microparticle formulation, to meet the World Health Organisation (WHO) requirements of combined tuberculosis therapy (WHO, 2014).

\section{Materials and Methods}

\subsection{Materials}

Locust bean gum (LBG, $\mathrm{C}_{30} \mathrm{H}_{50} \mathrm{O}_{26}, M_{w} 860 \mathrm{kDa}$ (Pollard et al., 2008)), poly (vinyl alcohol) (PVA, [-CH$\left.{ }_{2} \mathrm{CHOH}-\right]_{\mathrm{n}}, M_{w} 89-98 \mathrm{~g} / \mathrm{mol}$ ), isoniazid (INH, $\mathrm{C}_{6} \mathrm{H}_{7} \mathrm{~N}_{3} \mathrm{O}, M_{w} 137.14 \mathrm{~g} / \mathrm{mol}$ ), Tween $80^{\circledR}$, phosphate buffer saline (PBS) tablets pH 7.4, Dulbecco's modified Eagle's medium (DMEM), L-glutamine solution (200 mM), non-essential amino acids solution and penicillin/streptomycin (10000 units/mL, $10000 \mathrm{~g} / \mathrm{mL})$, trypsin-EDTA solution $(2.5 \mathrm{~g} / \mathrm{L}$ trypsin, $0.5 \mathrm{~g} / \mathrm{L}$ EDTA), trypan blue solution (0.4\%), phorbol 12-myristate 13-acetate (PMA, $\mathrm{C}_{36} \mathrm{H}_{56} \mathrm{O}_{8}$ ), thiazolyl blue tetrazolium bromide (MTT), N-(3dimethylaminopropyl)- $N$ '-ethylcarbodiimide hydrochloride (EDAC), Triton-X 100, sodium dodecyl sulfate (SDS), dimethylformamide (DMF), dimethyl sulfoxide (DMSO) and $\mathrm{HCl}$ were purchased from Sigma-Aldrich (Germany). Lactate dehydrogenase (LDH) kit was purchased from Takara Bio (Tokyo, Japan). Rifabutin (RFB, $\mathrm{C}_{46} \mathrm{H}_{62} \mathrm{~N}_{4} \mathrm{O}_{11}, M_{w} 847.00 \mathrm{~g} / \mathrm{mol}$ ) was supplied by Chemos (Germany) and fetal bovine serum (FBS) by Gibco (Life Technologies, 
USA). RPMI 1640 and Ham's F12 media were obtained from Lonza Group AG (Switzerland). Ultrapure water (MilliQ, Millipore, UK) was used throughout. All other chemicals were reagent grade.

\subsection{Cell lines}

A549 cells (human alveolar epithelium) and NR8383 cells (rat alveolar macrophages) were obtained from the American Type Culture Collection (ATCC, USA) and used in passages 27-37 and 9-18, respectively. THP-1 cells (human monocytes) were obtained from the Leibniz-Institut DSMZ (Germany) and used in passages 10-20. Cell cultures were grown in humidified 5\% $\mathrm{CO} 2 / 95 \%$ atmospheric air incubator at $37{ }^{\circ} \mathrm{C}$ (HerAcell 150, Heraeus, Germany). Cell culture medium (CCM) for A549 cells was DMEM supplemented with $10 \%$ (v/v) FBS, $1 \%$ (v/v) L-glutamine solution, 1\% (v/v) non-essential amino acids solution and 1\% (v/v) penicillin/streptomycin. For NR8383 cells, CCM consisted of Ham's F12 supplemented with 15\% (v/v) FBS, $1 \%(\mathrm{v} / \mathrm{v})$ L-glutamine and 1\% (v/v) penicillin/streptomycin, while THP-1 cells were grown in RPMI 1640 medium supplemented with 10\% (v/v) FBS, 1\% (v/v) L-glutamine and $1 \%(\mathrm{v} / \mathrm{v})$ penicillin/streptomycin.

THP-1 cells were grown in suspension and cell culture was maintained between $0.2 \times 10^{6}$ and $0.8 \times 10^{6}$ cells $/ \mathrm{mL}$. When reaching this higher concentration, cells were sub cultivated in new passage at the concentration of $0.2 \times 10^{6}$ cells $/ \mathrm{mL}$. Differentiation of THP-1 monocytes to provide the macrophage phenotype was performed using PMA $\left(0.2 \times 10^{6}\right.$ cells $/ \mathrm{mL}, 50 \mathrm{nM}, 48$ hours exposure $)$, after which the medium was replaced by fresh medium without PMA for 24 hours before the experiments. NR8383 cells grow in mixed culture (half population 
122 keeps adherent and half suspended). Adherent cells were those used to perform

123 the assays described below and their harvesting was made by scraping.

124

125

\subsection{Preparation of microparticles}

126

LBG microparticles, without drug and containing an association of the antitubercular drugs INH and RFB, were prepared by spray-drying, according to a previously reported protocol (Alves et al., 2016). The preparation of unloaded LBG microparticles involved grinding LBG in a glass mortar for $10 \mathrm{~min}$, after which $5 \mathrm{~mL} \mathrm{HCl} 0.1 \mathrm{M}$ were slowly added and grinding continued until complete mixture of powder and $\mathrm{HCl}$ solution was obtained. This was followed by the addition of purified water previously heated to $85^{\circ} \mathrm{C}$, up to a final volume of $50 \mathrm{~mL}$. The concentration of LBG in the final solution was $2 \%(\mathrm{w} / \mathrm{v})$. The solution was maintained under magnetic stirring for 30 min and subsequently placed on a water bath at $85^{\circ} \mathrm{C}$ under slow stirring for additional $30 \mathrm{~min}$. At the end, the solution was kept under stirring at room temperature overnight, until the moment of spray-drying.

For the production of drug-loaded microparticles, a solid dispersion of LBG and RFB was first prepared, by trituration in a mortar. After grinding, the same procedure used to prepare the LBG solution described above was applied. In parallel, INH was triturated in a mortar, being then solubilized with purified water under mild stirring for 10 minutes. The resulting solution was slowly added to the previously formed LBG/RFB solution immediately before spraydrying.

Microparticles were produced at LBG/INH/RFB mass ratio of 10/1/0.5 (final concentration of solids is $2.3 \%, \mathrm{w} / \mathrm{v}$ ) using a laboratory mini spray dryer (Büchi 
B-290, Büchi Labortechnik AG, Switzerland) operating in open mode and equipped with a high-performance cyclone. Protection from light was ensured for the whole process. The operating parameters were: inlet temperature: $160 \pm 2$ ${ }^{\circ} \mathrm{C}$; aspirator setting: $85 \%$; feed rate: $0.7 \pm 0.1 \mathrm{~mL} / \mathrm{min}$; and spray flow rate: 473 $\mathrm{L} / \mathrm{h}$. These conditions resulted in outlet temperature of $100 \pm 2{ }^{\circ} \mathrm{C}$. After spraydrying, microparticles were collected, placed in a dark flask and stored inside a desiccator until further use.

The spray-drying yield was calculated by gravimetry, comparing the total amount of solids initially added with the resultant weight of microspheres after spray-drying (Grenha et al., 2005).

Fluorescent (unloaded) microparticles of LBG or PVA were also prepared, to be used in the assay of macrophage capture. Covalent binding between fluorescein and the polymeric molecules was performed before microparticle production. To do so, LBG or PVA (1.0 g) were dissolved in $\mathrm{HCl}$ solution $\left(10^{-4} \mathrm{M}\right)$ at a concentration of $1 \%(\mathrm{w} / \mathrm{v})$. LBG solution was applied the same treatment described above for the preparation of LBG microparticles. PVA solution was maintained at $80{ }^{\circ} \mathrm{C}$ under stirring overnight. Fluorescein (43 mg) was dissolved in ethanol 96\% (v/v) and added to the previously formed LBG or PVA solutions. EDAC (ca. $33 \mathrm{mg}$ ) was dissolved in milli-Q water and added to the solution. This was kept under stirring for $72 \mathrm{~h}$ and then dialysed (2000 Da $M_{w}$ cut off) against water. Light protection was ensured in the whole process. The resulting suspension was frozen and freeze-dried (FreeZone Benchtop Freeze Dry System, Labconco, USA). The fluorescently-labelled polymers were stored in a desiccator until further use, under light protection. Fluorescent microparticles were produced by spray-drying. The used conditions were the same described 
172 above for LBG, while the following were used for PVA: inlet temperature: $155 \pm$

$1732{ }^{\circ} \mathrm{C}$; aspirator setting: $80 \%$; feed rate: $1.0 \pm 0.1 \mathrm{~mL} / \mathrm{min}$; and spray flow rate:

$174473 \mathrm{~L} / \mathrm{h}$. These conditions resulted in outlet temperature of $96 \pm 2{ }^{\circ} \mathrm{C}$.

175

\subsection{Characterisation of microparticles}

177

2.4.1. Morphology

178 The surface morphology of LBG microparticles was characterised by field 179 emission scanning electron microscopy (FESEM; FESEM Ultra Plus, Zeiss, 180 Germany). Dry powders were placed onto metal plates and $5 \mathrm{~nm}$ thick iridium 181 film was sputter-coated (model Q150T S/E/ES, Quorum Technologies, UK) on 182 the samples before viewing.

\subsubsection{Feret's diameter}

Microparticle size was estimated as the Feret's diameter and was directly determined by optical microscopy (Microscope TR 500, VWR international, Belgium) from the manual measurement of 300 microparticles $(n=3)$.

\subsubsection{Density}

Real density $\left(\mathrm{g} / \mathrm{cm}^{3}\right)$ was determined using a Helium Pycnometer (Micromeritics AccuPyc 1330, Germany) $(\mathrm{n}=3)$. Tap density $\left(\mathrm{g} / \mathrm{cm}^{3}\right)$ was determined using a tap density tester (Densipro 250410, Deyman, Spain), by measuring the volume of a known weight of powder before and after tapping, respectively $(n=3)$. The determination of tap density involved tapping the sample until no further reduction of powder volume was observed (average of 180 taps). 
The determination of microparticle drug content was performed by UV-Vis spectrophotometry (Pharmaspec UV-1700, Shimadazu, Japan), at $265.5 \mathrm{~nm}$ for INH and $500 \mathrm{~nm}$ for RFB. A screening of the matrix material (LBG) revealed no interference at the selected wavelengths.

202 In order to determine the drug content, a certain amount of drug-loaded microparticles was incubated with $\mathrm{HCl} 0.1 \mathrm{M}$, under magnetic stirring for 60 min, which ensures complete dissolution of the carriers. Samples were then centrifuged (8000 rpm, $30 \mathrm{~min} ; 5810 \mathrm{R}$, Eppendorf, Germany) and filtered (0.45 $\mu \mathrm{m})$ before quantification. Calibration curves were performed at $265.5 \mathrm{~nm}$ for INH and at both this wavelength and at $500 \mathrm{~nm}$ for RFB, using the medium of dissolution of unloaded microparticles. The latter curve was used to determine the concentration of RFB and the former allowed the determination of the fraction of the absorbance at $265.5 \mathrm{~nm}$ that is due to RFB, the remainder being attributable to $\mathrm{INH}$, thus allowing the determination of its concentration through

212 the corresponding calibration curve. Drug association efficiency (AE) and microparticle (MP) loading capacity (LC) were estimated as follows $(n=3)$ : $\mathrm{AE}(\%)=($ Real amount of drug on MP / Theoretical amount of drug on MP $) \mathrm{x}$ 100 (Eq. 1)

LC $(\%)=($ Real amount of drug on MP/ Weight of MP) $x 100$ (Eq. 2)

\subsection{Aerodynamic characterisation of microparticles}

HPMC size 3 capsules (Quali-V-I, Qualicaps, Spain) were filled with $22.5 \mathrm{mg}$ of LBG/INH/RFB powder. The content of four capsules was discharged in each aerodynamic test using the medium resistance $\mathrm{RS}_{0} 1^{\circledR}$ inhaler (Plastiape Spa, 
Italy) and experiments were performed in triplicate. The device was connected to the Andersen cascade impactor (ACI, Copley Scientific, UK) operated at $60 \mathrm{~L} / \mathrm{min}$, ensuring a pressure drop of $4 \mathrm{kPa}$ through the device. This was activated for $4 \mathrm{~s}$ in order to let $4 \mathrm{~L}$ of air passing through the system, thus complying with the standard procedure described by USP 38 and Ph.Eur.8 (Ph.Eur., 2014; USP, 2015).

ACI separates particles according to their aerodynamic diameter and it was assembled using the appropriate adaptor kit for the $60 \mathrm{~L} / \mathrm{min}$ air flow test. Cutoffs of the stages from -1 to 6 are the following: 8.60, 6.50, 4.40, 3.20, 1.90, $1.20,055,0.26 \mu \mathrm{m}$. A glass fiber filter (Whatman, Italy) was placed right below stage 6 in order to collect particles with diameter lower than that of stage 6 cutoff.

The plates of the impactor were coated with a thin layer of ethanol containing $1 \%(\mathrm{w} / \mathrm{v})$ Tween 20 to prevent particle bounce. The drugs were recovered from the apparatus with water/acetonitrile mixture $(50 / 50, \mathrm{v} / \mathrm{v})$ and quantified by HPLC (Agilent 1200 series, Germany). A LiChrospher ${ }^{\circledR} 100$ RP-18 (5 $\left.\mu \mathrm{m}\right)$ column of $4 \mathrm{~mm}$ i.d. $\times 250 \mathrm{~mm}$ length with security guard cartridge was used. The eluent was a mixture of phosphate buffer $\mathrm{pH}=7$ (A) and acetonitrile (B) at a flow rate of $1 \mathrm{~mL} / \mathrm{min}$, starting with $\mathrm{A} / \mathrm{B}=95: 5$ and kept for $5 \mathrm{~min}$, followed by a 7 min step gradient, until a 20:80 A/B ratio was reached, which was then

242 kept for $16 \mathrm{~min}$. Detection was performed by a diode array detector at $275 \mathrm{~nm}$.

243 The used chromatographic conditions were: gradient flow (Phosphate buffer $\mathrm{pH}$ $244=7$ (A), acetonitrile (B); A/B from 95:5 in the first $5 \mathrm{~min}$ it is changed to $20: 80$ in $7 \mathrm{~min}$ and kept in this 20:80 during other $16 \mathrm{~min}$ ). A linear calibration plot for INH and RFB was obtained over the range $10-400 \mu \mathrm{g} / \mathrm{mL}(\mathrm{n}=3)$. Under these 
247 conditions, the retention times of INH and RFB were 4.7 and $17.4 \mathrm{~min}$, 248 respectively.

249 The quantification of drug deposited inside the impactor allows calculating 250 different aerodynamic parameters. The emitted dose (ED) is the amount of drug 251 ex-device, considered the total amount of drug collected in the impactor, 252 quantified by HPLC (induction port, stages -1 to 6 and filter). The mass median aerodynamic diameter (MMAD) was determined by plotting the cumulative percentage of mass less than the stated aerodynamic diameter on probability scale versus aerodynamic diameter on logarithmic scale. The fine particle dose (FPD) corresponds to the mass of drug particles with aerodynamic diameter lower than $5 \mu \mathrm{m}$ calculated using the particle size distribution equation obtained from the ACI analysis. The fine particle fraction (FPF) is the ratio between the FPDs and the MD.

The drug recovery ranged between $77-91 \%$ in all the experiments, being thus coincident with the requisites of the pharmacopeia (Buttini et al., 2013).

\subsection{Determination of drug release profile}

264 The determination of drug release was performed in PBS pH 7.4 added of $1 \%$

$265(\mathrm{v} / \mathrm{v})$ Tween $80^{\circledR}$. The assay respected sink conditions, as the maximum amount of drug was always below $30 \%$ of its maximum solubility (EMA, 2014). INH solubility was considered $274 \pm 4.79 \mathrm{mg} / \mathrm{mL}$ (Hiremath and Saha, 2008), while that of RFB was determined experimentally to be $0.496 \mathrm{mg} / \mathrm{mL}$ (Alves et al., 2016). A determined amount of microparticles $(20 \mathrm{mg})$ was incubated with the medium $(10 \mathrm{~mL})$, at $37{ }^{\circ} \mathrm{C}$, under mild shaking (100 rpm, orbital shaker OS 20 ,

271 Biosan, Latvia). Samples (1 mL) were periodically collected and the amount of 
272 each drug quantified as indicated above $(n=3)$. Direct quantification applied for

273 RFB, while INH required dilution (1:10). A calibration curve was performed

274 using the medium resulting from the incubation of unloaded LBG

275 microparticles, after centrifugation $(8000 \mathrm{rpm}, 60 \mathrm{~min})$ and filtration $(0.45 \mu \mathrm{m})$.

276

277

2.7. In Vitro Biocompatibility Study

\subsubsection{Cell viability evaluation by MTT test}

279 The evaluation of cell viability upon exposure to LBG/INH/RFB microparticles was performed by the MTT assay, using two cell lines of high relevance within the scope of tuberculosis infection, A549 and macrophage-differentiated THP-1 cells. A549 cells were seeded at a density of $1 \times 10^{4}$ cells/well on 96-well plates (Orange Scientific, Belgium), in $100 \mu \mathrm{L}$ of complete DMEM. Cells were incubated for $24 \mathrm{~h}$ at $37^{\circ} \mathrm{C}$ in $5 \% \mathrm{CO}_{2}$ atmosphere before use. THP-1 cells were differentiated with PMA to obtain the macrophage-phenotype before the experiments, according to the procedure described above, with the necessary adaptations. THP-1 cells were seeded on 96 -well plates $\left(0.035 \times 10^{6}\right.$ cells/well $)$ in $100 \mu \mathrm{L}$ of RPMI supplemented with $50 \mathrm{nM}$ of PMA and incubated for $48 \mathrm{~h}$ at $37^{\circ} \mathrm{C}$ in $5 \% \mathrm{CO}_{2}$ atmosphere. After that time, $\mathrm{CCM}$ was renewed for other $24 \mathrm{~h}$, before the experiments.

291

Microparticles (unloaded or drug-loaded) were exposed in the form of a suspension prepared in pre-warmed CCM without FBS and evaluated at the concentrations of 0.1 and $0.5 \mathrm{mg} / \mathrm{mL}$ (includes polymers and drugs), for 3 and $24 \mathrm{~h}$. INH and RFB were also tested as free drugs, at concentrations representing their loading in microparticles $(0.01$ and $0.05 \mathrm{mg} / \mathrm{mL}$ for $\mathrm{INH} ; 0.005$ and 0.025 $\mathrm{mg} / \mathrm{mL}$ for RFB). 
297 MTT solution $(0.5 \mathrm{mg} / \mathrm{mL}$ in PBS, $\mathrm{pH} 7.4)$ was added after the exposure time (in 298 A549 cells, samples were previously removed; in THP-1 cells no removal was 299 applied) and incubated for $2 \mathrm{~h}$, after which formazan crystals were solubilised with DMSO (A549 cells) or 10\% SDS in a 1:1 mixture of DMF:water (THP-1 cells) and the absorbance measured by spectrophotometry (Infinite M200,

302 Tecan, Austria). The viability of untreated cells was assumed to correspond to $100 \%$ of cell viability, and viability of treated cells was compared to this control. The assay was replicated at least three times, each with six replicates.

305

\subsubsection{Determination of cell membrane integrity}

307 The integrity of cell membrane after exposure to LBG microparticles was determined by the quantification of LDH released by cells. This was performed in A549 and macrophage-differentiated THP-1 cells upon $24 \mathrm{~h}$ exposure to a concentration of $0.5 \mathrm{mg} / \mathrm{mL}$ of unloaded or drug-loaded LBG microparticles. The chosen concentration corresponds to the maximum concentration tested in the MTT assay. Free INH and RFB were also tested as controls $(0.05 \mathrm{mg} / \mathrm{mL}$ for INH; $0.025 \mathrm{mg} / \mathrm{mL}$ for RFB).

314 Cells were cultured in 96-well plates in the conditions described before for the MTT assay (the assays were performed simultaneously). Upon exposure, cell culture supernatants were collected, centrifuged $\left(16000 \mathrm{x} \mathrm{g}, 5 \mathrm{~min}, 4^{\circ} \mathrm{C}\right)$ and

317 processed using a commercial kit. Absorbances were measured by spectrophotometry (Infinite M200, Tecan, Austria) at a wavelength of $490 \mathrm{~nm}$ (background correction at $690 \mathrm{~nm}$ ).

A negative control of LDH release was performed incubating cells with CCM only and Triton-X 100 (10\%) was used as positive control, being assumed as 
$100 \%$ LDH release. Released LDH upon incubation with each sample was

323

324

325

326

327

determined by comparison with the positive control. All measurements were performed in triplicate.

\subsection{Macrophage capture of LBG microparticles}

The determination of macrophage ability to capture microparticles was determined in vitro in two cell lines, differentiated THP-1 cells and NR8383 cells. The latter were seeded $\left(1.0 \times 10^{6}\right.$ cells per well $)$ in 6 -well plates for adhered cells, with $2 \mathrm{~mL}$ of Ham's F12 medium. This procedure was performed $24 \mathrm{~h}$ before the test to ensure the adhesion of 50 to $75 \%$ of the original population. THP-1 cells $\left(2.0 \times 10^{5}\right.$ cells $\left./ \mathrm{mL}\right)$ were suspended in RPMI medium supplemented with $50 \mathrm{nM}$ PMA and seeded at $5 \mathrm{~mL} /$ well in 6-well plates for cells in suspension.

The evaluation of microparticle uptake by macrophages was performed by flow cytometry (FacScalibur cell analyser, BD Biosciences, Belgium) upon exposure to LBG and PVA microparticles $\left(50 \mu \mathrm{g} / \mathrm{cm}^{2}\right)$, both fluorescently-labelled. PVA microparticles were used as control. Microparticles were aerosolised onto the macrophage layer using the Dry powder Insufflator ${ }^{\mathrm{TM}}$ (Model DP-4, PennCentury $^{\mathrm{TM}}$, USA) and 2 hours incubation at $37^{\circ} \mathrm{C}$ was allowed, without CCM (only a residual amount of medium was kept to ensure the hydration of cell surface). The phagocytic process was stopped by the addition of a cold solution of PBS.3\% FBS (5 mL, two applications), which also provided washing. Cells were scraped and centrifuged $(1500 \mathrm{rpm}, 2 \mathrm{~min}$, room temperature, centrifuge MPW - 223e, MedInstruments, Poland) in $2 \mathrm{~mL}$ of PBS.3\% FBS. The cycle of resuspension in PBS.3\% FBS and centrifugation was repeated thrice. At the end, 
347 cells were re-suspended in $1 \mathrm{~mL}$ of PBS.3\% FBS, transferred to cytometry tubes

348 (BD Biosciences, Belgium) and maintained at $4{ }^{\circ} \mathrm{C}$ until the analysis.

349 In flow cytometry, FSC-H and SSC-H channels were used, respectively, to 350 measure size and granularity of cells, while side scatter light was used to identify 351 cell viable population. The amount of cells exhibiting a fluorescent signal was 352 considered to have phagocytosed microparticles. The assay for each dose was replicated at least three times.

\subsection{Statistical analysis}

The student t-test and the one-way analysis of variance (ANOVA) with the pairwise multiple comparison procedures (Holm-Sidak method) were performed to compare two or multiple groups. For the analysis of results of in vitro release assay, a two-way ANOVA with Bonferroni's method for multiple comparison test was used. All analysis were run using the GraphPad Prism (version 6.07) and differences were considered to be significant at a level of $\mathrm{p}<0.05$.

\section{Results and Discussion}

\subsection{Preparation and characterisation of LBG/INH/RFB microparticles}

LBG microparticles loaded with a combination of the first-line antitubercular drugs INH and RFB were successfully obtained by spray-drying, with yields of $60-70 \%$. The used concentration of LBG $(2 \%, \mathrm{w} / \mathrm{v})$ was chosen from previous experiments (unpublished data) in order to provide suitable microparticle size for the purpose of lung delivery, along with acceptable spray-drying yield. Theoretical drug loadings of $8.70 \%$ (INH) and $4.35 \%$ (RFB) were selected because they provide microparticles without the formation of aggregates, in 
372 micron-size range, which are capable to deliver the two drugs in combination.

373 LGB was selected because of its potential to enhance macrophage uptake and the

374 amount of polymer was kept purposely high in order to favour internalisation.

375 The morphological observation of LBG-based microparticles, unloaded or drug-

376 loaded, revealed irregular shapes with convoluted surface (Figure 1), without

377 any evident effect resulting from drug association. The latter was actually

378 expected because loadings are relatively low. Similar observations on the

379 morphology and the absence of effect of drug association were reported in a

380 previous work with LBG microparticles associating either INH or RFB

381 separately (Alves et al., 2016).

382

383

384

385

386

387

388

389

390

391
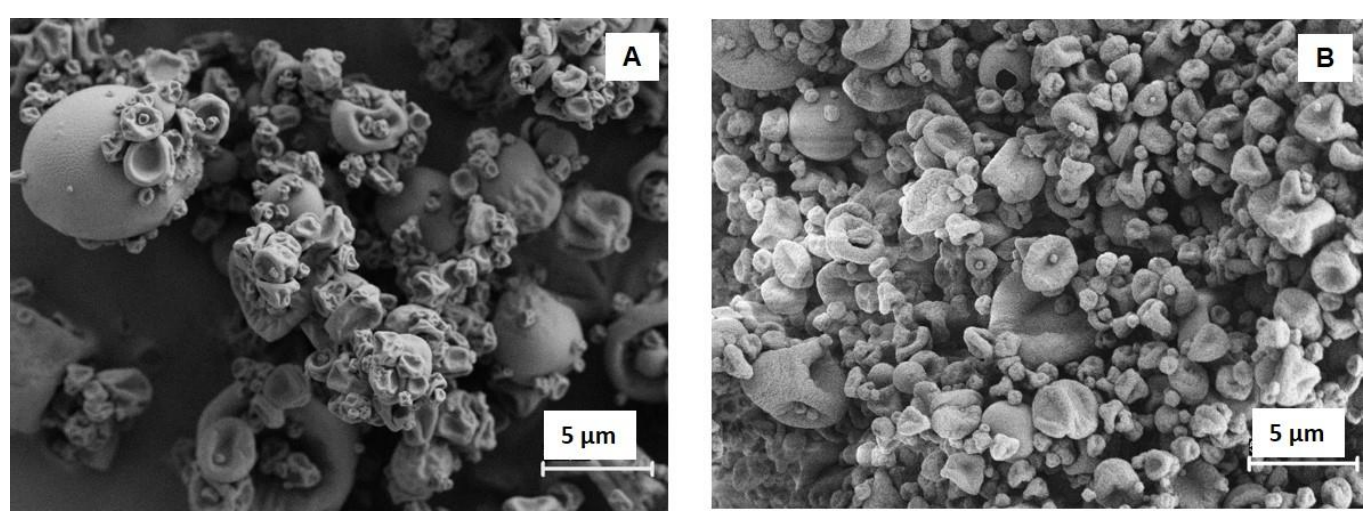

Figure 1. Microphotographs of LBG-based microparticles viewed by scanning electron microscopy: A) Unloaded LBG microparticles; B) LBG/INH/RFB (10/1/0.5, w/w) microparticles. INH: isoniazid, LBG: locust bean gum, RFB: rifabutin.

The determined Feret's diameters were rather low, $1.35 \pm 0.7 \mu \mathrm{m}$ for unloaded LBG microparticles and $1.14 \pm 0.51 \mu \mathrm{m}$ for drug-loaded microparticles. Real densities were around $1.4 \mathrm{~g} / \mathrm{cm}^{3}$ and tap densities varied between 0.2 and 0.37 $\mathrm{g} / \mathrm{cm}^{3}$. These values are in the same range of others reported for spray-dried 
polysaccharide microparticles (Dalpiaz et al., 2015; Pai et al., 2015; Rassu et al., 2015).

394 The encapsulation of both antibiotics was very high, $94 \%$ for INH and $102 \%$ for RFB, as indicated in Table 1. The resulting loading capacities were, thus, close to theoretical maximum, being of $8.2 \%$ and $4.4 \%$ for INH and RFB, respectively. Spray-drying is a method usually reported to lead to high efficiency of drug association (Peltonen et al., 2010), as also corroborated in the present work. Moreover, the obtained results are in line with the high association efficiencies reported for each drug when associated individually (Alves et al., 2016).

402 Table 1. Drug association efficiency and loading capacity of

LBG/INH/RFB (10/1/0.5, w/w) microparticles (mean $\pm \mathrm{SD}, \mathrm{n}=3$ ).

\begin{tabular}{ccc}
\hline Drug & Association efficiency (\%) & Loading capacity (\%) \\
\hline INH & $94.4 \pm 3.3$ & $8.2 \pm 0.3$ \\
RFB & $102.1 \pm 1.1$ & $4.4 \pm 0.1$ \\
\hline
\end{tabular}

404

INH: isoniazid; RFB: rifabutin

405

406

3.2. Aerodynamic behaviour of LBG/INH/RFB microparticles

407 Considering the intended application in lung delivery, the determination of 408 aerosolisation properties stands as the most important aspect in the design of inhalable dry powders. The in vitro aerosol performance was determined using a RS0 $1{ }^{\circledR}$ dry powder inhaler and the aerodynamic properties determined upon assessment in the ACI are displayed in Table 2. 
Table 2. Aerodynamic characteristics of LBG/INH/RFB (10/1/0.5, w/w)

415 microparticles (mean $\pm \mathrm{SD}, \mathrm{n}=3$ ). Loaded powder amount $=22.5 \mathrm{mg}$, 416 containing $7.8 \mathrm{mg}$ INH and $3.9 \mathrm{mg}$ RFB, respectively.

\begin{tabular}{llllll}
\hline Drug & $\begin{array}{l}\text { Emitted dose } \\
(\boldsymbol{\%})\end{array}$ & MMAD $(\boldsymbol{\mu m})$ & GSD $(\boldsymbol{\mu m})$ & FPD $(\mathbf{m g})$ & FPF $(\boldsymbol{\%})$ \\
\hline INH & $92.6 \pm 0.9$ & $6.2 \pm 0.6$ & $2.4 \pm 0.7$ & $2.7 \pm 0.6$ & $38.0 \pm 1.6$ \\
RFB & $92.0 \pm 0.5$ & $5.8 \pm 0.3$ & $2.8 \pm 0.2$ & $1.3 \pm 0.1$ & $38.1 \pm 1.8$
\end{tabular}

FPD: fine particle dose; FPF: fine particle fraction; GSD: geometric standard deviation; INH: isoniazid; MMAD: mass median aerodynamic diameter; RFB: rifabutin

The dose emitted from the inhaler was very satisfactory, reaching $92 \%$. This is indicative of the favourable properties of the material LBG to produce microparticles by spray-drying with good flowing capacity. However, a consistent amount of powder impacted on the high stages of the impactor, leading to MMAD value equal to 5.8 and $6.2 \mu \mathrm{m}$ for RFB and INH, respectively. This is due to incomplete deaggregation of microparticle clusters during the product aerosolisation. It is well known that the aerodynamic performance of a dry powder inhaler (DPI) is strongly affected by both the device and the formulation characteristics. However, the spinning movement of the capsule inside the inhaler used in this study has demonstrated to be the most efficient in powder deaggregation in comparison with other capsule-based DPI (Martinelli et al., 2015). Hence, the optimisation of microparticles, with size, shape and density promoting their aerodynamic behavior will be addressed in the future, in order to increase the amount of LBG/INH/RFB fine particles capable of reaching the target site of alveoli. Nevertheless, LBG/INH/RFB microparticles showed a FPF of $38 \%$, indicating that $38 \%$ of the microparticles have aerodynamic diameter below $5 \mu \mathrm{m}$, thus having the necessary conditions to reach the respiratory zone. This value is in agreement with those usually determined for 
high doses antibiotic powder formulated without lactose as carrier (Belotti et al., 2015; Maretti et al., 2016).

440 Figure 2 shows the stage-by-stage deposition profiles of both drugs encapsulated 441 in the tested microparticles. The similarity of the profiles indicates that the two 442 drugs were equally co-deposited on the different stages. This supports the 443 decision of developing a carrier with drug combination, as the microparticles demonstrate to have homogeneous composition, leading to a co-deposition of 445 drugs.

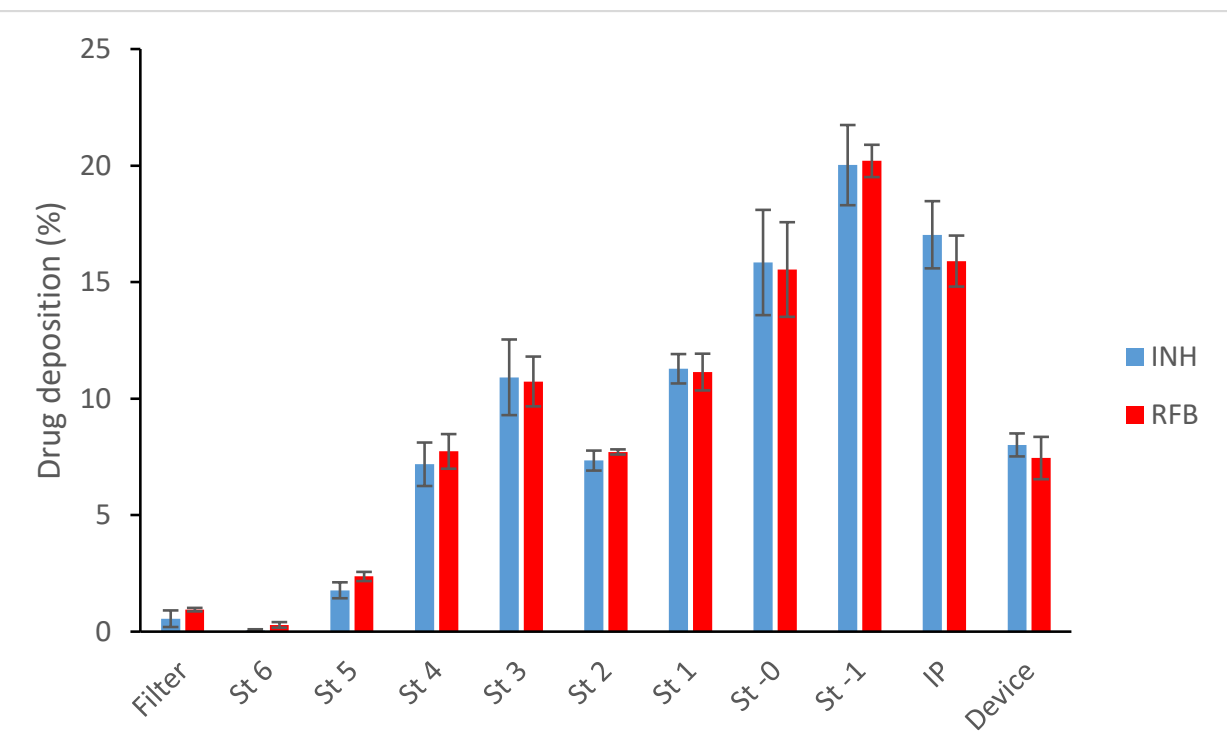

447 Figure 2. Stage-by-stage deposition profiles of isoniazid and rifabutin inside the Andersen cascade impactor after RS01 aerosolisation at $60 \mathrm{~L} / \mathrm{min}$, inhalation $4 \mathrm{~L}$ (values are mean $\pm \mathrm{SD}, \mathrm{n}=3$ ).

\subsection{In vitro drug release from LBG microparticles}

Release studies were performed in PBS pH 7.4 added of $1 \%$ Tween $80^{\circledR}$. In this way, the local $\mathrm{pH}$ of the alveolar zone is resembled, along with the content of surfactant (Kyle et al., 1990), and the dissolution of RFB is ensured (Alves et al., 2016). The release profile determined for each drug is depicted in Figure 3. 


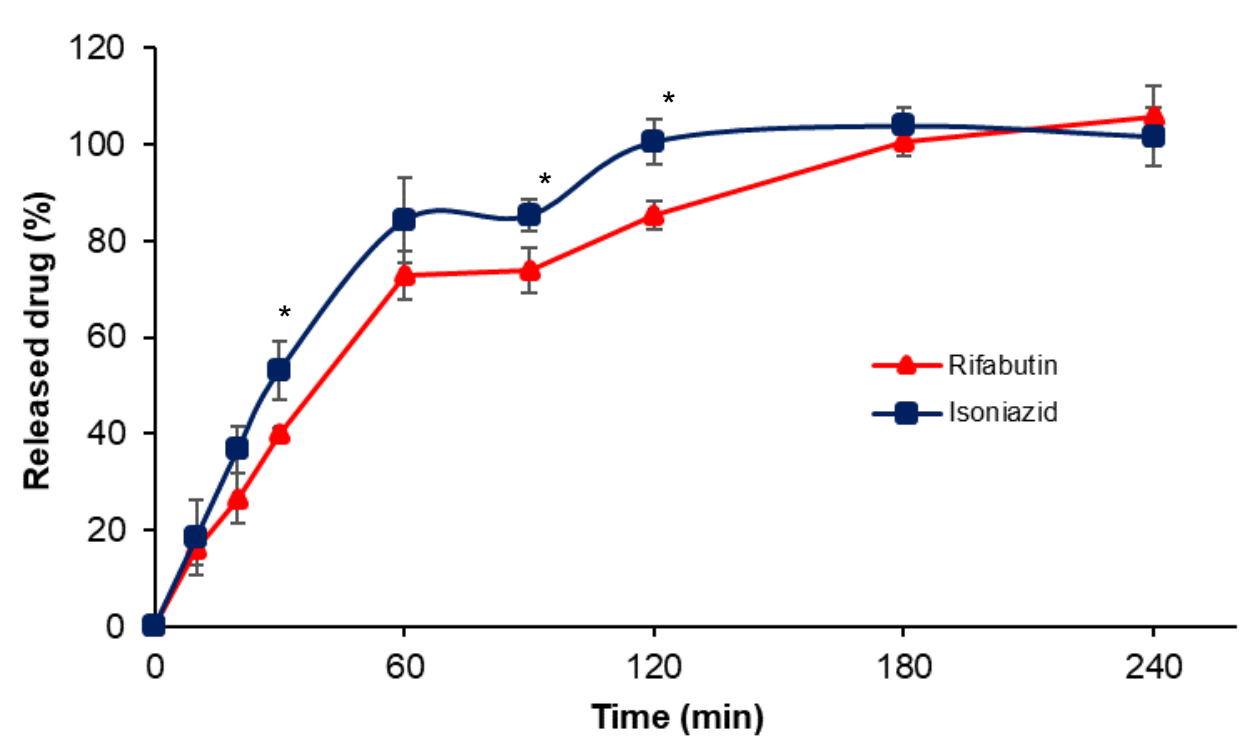

Figure 3. In vitro release of isoniazid (INH) and rifabutin (RFB) from 466 LBG/INH/RFB (10/1/0.5, w/w) microparticles, in PBS pH $7.4-1 \%$ Tween $80^{\circledR}$ at $37^{\circ} \mathrm{C}$ (LBG: locust bean gum; mean $\pm \mathrm{SD}, \mathrm{n}=3$ ). ${ }^{*} \mathrm{p}<0.05$ comparing release of two drugs.

As can be observed, the release of the drugs is rapid, at 30 min $40 \%$ (RFB) $47150 \%(\mathrm{INH})$ of the antibiotics being already available. At $60 \mathrm{~min}$, the values reach $73 \%$ for RFB and $84 \%$ for $\mathrm{INH}$. Although the profile is very similar for both antibiotics, RFB release is somewhat slower than that of INH, with statistically significant differences at some time-points $(30,90$ and $120 \mathrm{~min}, \mathrm{p}<$ 475 0.05). The higher release of INH is a consequence of its higher solubility in 476 aqueous media (O'Neil, 2006). Considering the conditions of the assay, the rapid 477 release was expected, as LBG is a hydrophilic polymer and rapidly dissolved, 478 releasing the associated drugs. Despite this observation, slower drug release is 479 expected to occur in vivo, as has been reported (Bur et al., 2010; Haghi et al., 480 2014). When reaching the alveoli, microparticles will deposit on an epithelium 
covered by the lung lining fluid (Fröhlich et al., 2016), which is estimated to

482 have $0.01-0.1 \mu \mathrm{m}$. In this manner, deposited particles will not be immersed,

483

484

485

486

487

488

489

490

491

492

493

494

495

496

497

498

499

500

501

502

503

504

505

only a small part being in direct contact with fluid instead and, therefore, erosion and dissolution will initiate from underneath the microparticles (Bur et al., 2010; Haghi et al., 2014). Ultimately, this will result in slower release and is also a relevant observation towards the objective of having particle uptake by macrophages before complete dissolution and drug release.

\subsection{In vitro cytotoxicity of LBG microparticles}

Two complementary cell viability assays were used to test the effect of LBG/INH/RFB microparticles, the metabolic assay MTT and the LDH release assay, which assesses cell membrane integrity. Considering the environment underlying tuberculosis pathogenesis, alveolar epithelial cells (A549) and macrophage-like cells (macrophage-differentiated THP-1 cells) were used. Microparticle concentrations of 0.1 and $0.5 \mathrm{mg} / \mathrm{mL}$ were tested. These are concentrations typically reported in the assessment of lung drug carriers, despite being possibly overestimated if an alveolar area of $100 \mathrm{~m}^{2}$ is considered (Fröhlich et al., 2016). Unloaded microparticles and free drugs were tested as controls.

Regarding the MTT assay, as can be observed in Figure $4 \mathrm{~A}$ and $4 \mathrm{~B}$, the exposure of A549 cells to drug-loaded microparticles induced very similar results after $3 \mathrm{~h}$ or $24 \mathrm{~h}$, evidencing an absence of time-dependent effect. However, there is a clear concentration-dependent effect $(\mathrm{p}<0.05)$, visible at both time-points, as the resulting cell viability decreases from $72 \%$ to $57 \%$ (at 24

h) as the concentration of microparticles increases from 0.1 to $0.5 \mathrm{mg} / \mathrm{mL}$. 
506 Similar observations regarding the effect of time and concentration resulted from

507 the incubation with unloaded LBG microparticles, although in that case cell

508 viabilities remained well above the $70 \%$ considered the threshold beyond which

509 a toxic effect is occurring (ISO, 2009).

510
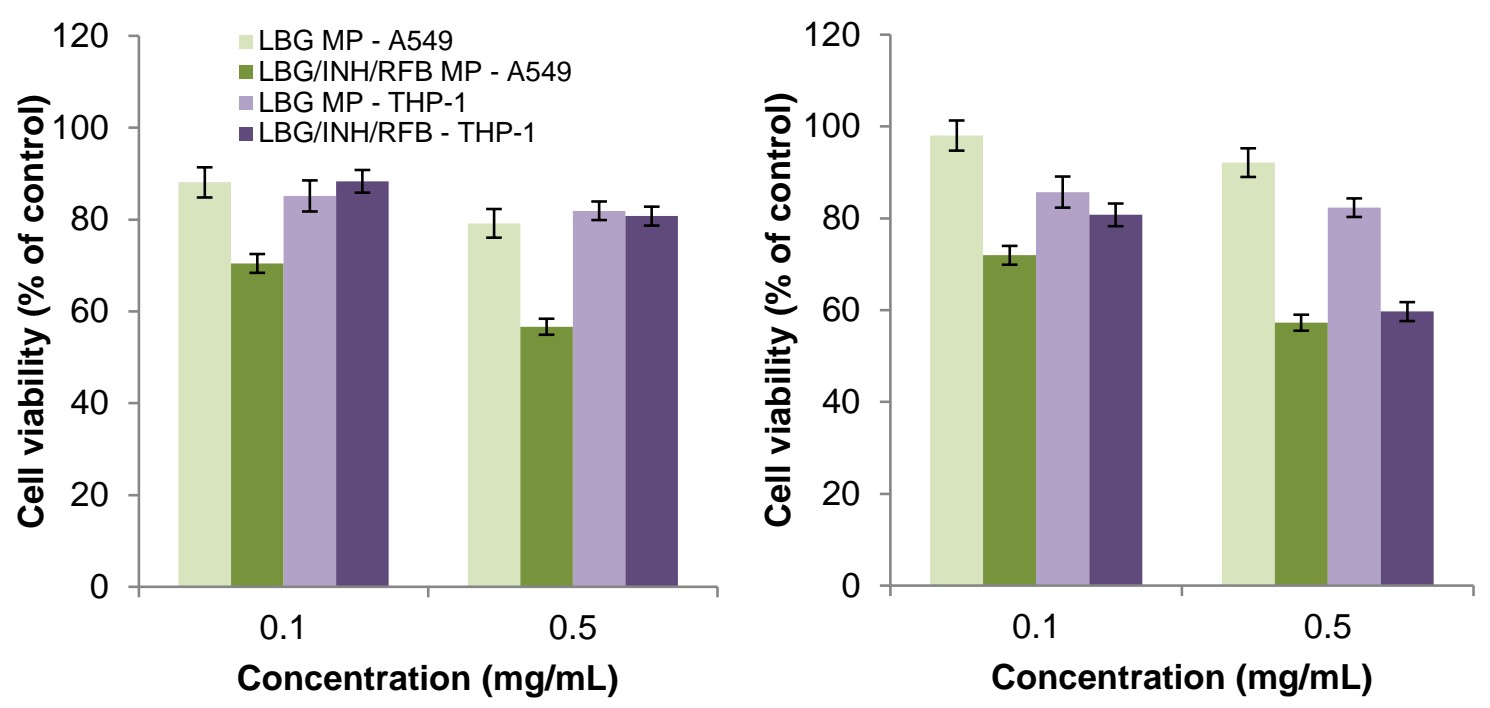

511

512 Figure 4. A549 and macrophage-like THP-1 cell viability after A) $3 \mathrm{~h}$ and B) 24

$513 \mathrm{~h}$ exposure to unloaded LBG and LBG/INH/RFB (10/1/0.5, w/w) microparticles

514 (MP); C) $24 \mathrm{~h}$ exposure to INH as free drug and D) $24 \mathrm{~h}$ exposure to RFB as free

515 drug. Data represent mean \pm SEM $(n=3$, six replicates per experiment at each

516 concentration). Dashed line represents $70 \%$ cell viability (INH: isoniazid; LBG:

517 locust bean gum; MP: microparticles; RFB: rifabutin).

519 Macrophage-differentiated THP-1 cells showed a somewhat different behaviour,

520 apparently being less sensitive to the contact with drug-loaded microparticles

521 after short-time exposure (3 h, Figure 4A). Indeed, at that time-point, while

522 A549 cells registered $57 \%$ cell viability for the concentration of $0.5 \mathrm{mg} / \mathrm{mL}$, macrophage-like THP-1 cells remained at $81 \%$. Nevertheless, the prolongation 
of the exposure to $24 \mathrm{~h}$ (Figure 4B) decreased cell viability to 60\%, which is similar to the $57 \%$ registered for A549 cells.

526 The results obtained on both cell lines are comparable to those reported for RFB-

527 loaded LBG microparticles in a previous work and the opposite of those 528 obtained for INH-loaded microparticles (Alves et al., 2016). This suggests that 529 the negative effect of drug-loaded microparticles on cell viability is certainly due, at least in part, to the RFB content. The $\mathrm{pH}$ of microparticle suspension in cell culture medium that is incubated with cells is around 7.2, so that is not expected to have a negative contribution. As shown in Figure $4 \mathrm{C}, \mathrm{INH}$ has no effect on cell viability in any of the tested conditions (concentrations, cell lines) at $24 \mathrm{~h}$ when exposed as free drug. An exposure of $3 \mathrm{~h}$ similarly generated viabilities around 90-100\%, not only for INH, but also for RFB (data not shown). In turn, free RFB (Figure 4D) was observed to induce a decrease of A549 cell viability to $65 \%$ after $24 \mathrm{~h}$ exposure to the higher concentration, which correlates well with the results observed in the same cell line for drugloaded microparticles, although in that case viability was even lower (57\%).

540 However, a different behaviour was observed in THP-1 cells, which viability 541 remained at $85 \%$ upon $24 \mathrm{~h}$ exposure to the same concentration of free RFB.

542 Several reports on the literature indicate higher susceptibility of A549 cells 543 comparing with THP-1 cells (Lankoff et al., 2012; Singh et al., 2015). This is 544 generally observed in our results, where THP-1 cells frequently show higher cell viability in the same testing conditions. The fact that THP-1 cells have $85 \%$ cell viability when exposed to $0.5 \mathrm{mg} / \mathrm{mL}$ RFB and then register $60 \%$ when exposed

547 to the same amount of antibiotic encapsulated in LBG microparticles, is possibly 548 attributed to the phagocytic capacity of these cells (Lankoff et al., 2012). This 
549 characteristic certainly mediates a more intense contact of the cells with RFB,

550 leading to a reduction of cell viability (Lanone et al., 2009). As referred above 551 for A549 cells, unloaded LBG microparticles were also tested as control in 552 macrophage-differentiated THP-1 cells (Figure 4A and B), resulting in cell 553 viabilities above $80 \%$ in all cases. Overall, this is a general indication on the 554 absence of any deleterious effect of the polysaccharide on cell viability under the 555 tested conditions.

556 The amount of the cytoplasmic enzyme LDH released after 24 h contact with the 557 higher concentration of microparticles and free drugs was also determined 558 (Figure 5). The results essentially corroborate those of the MTT, with 559 LBG/INH/RFB microparticles having the more intense effect on released LDH, 560 which is similar in both cell lines. The incubation with CCM generated $21 \%$ 561 LDH release in A549 cells and 38\% in macrophage-differentiated THP-1 cells.

562 The free drugs (INH and RFB) and LBG MP revealed an effect similar to that of 563 the CCM in each cell line, with no significant differences in released LDH. On 564 the contrary, LBG/INH/RFB microparticles induced significantly higher release 565 of LDH in both cell lines, 58\% in A549 cells and 60\% in THP-1 cells ( $<<0.05)$. 


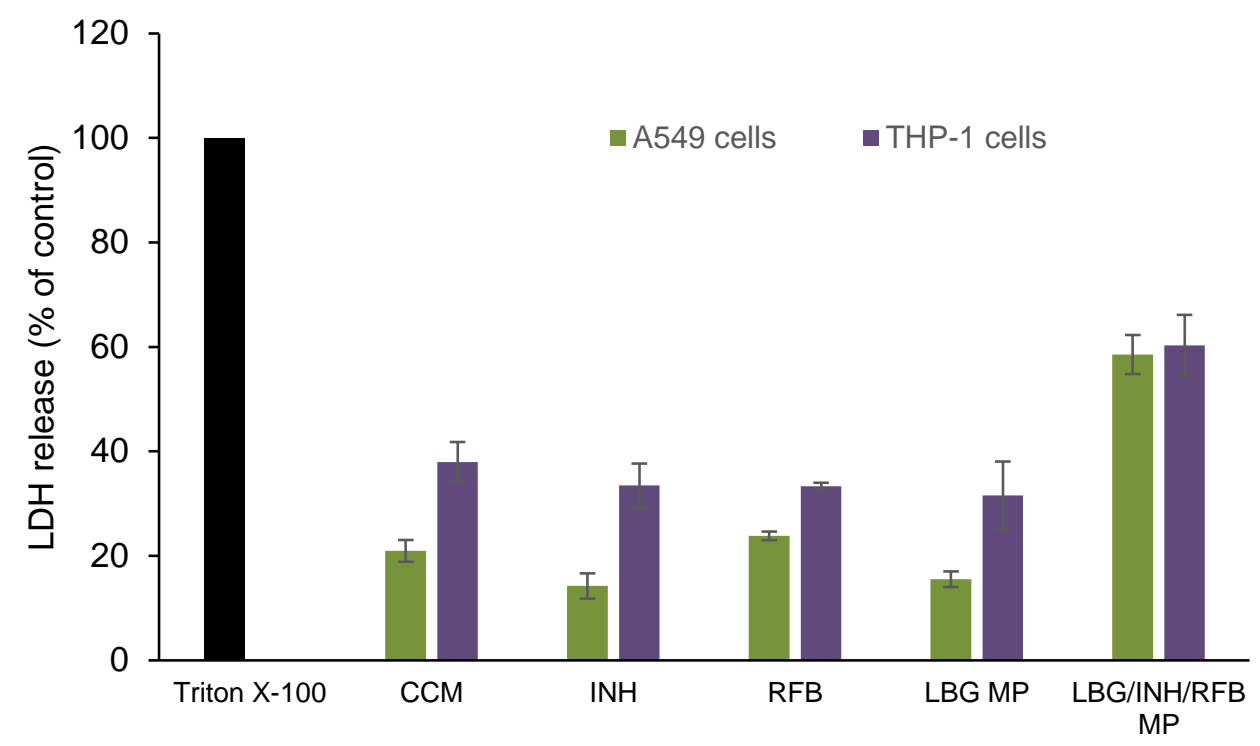

566

567 Figure 5. LDH released from A549 and macrophage-like THP-1 cells after $24 \mathrm{~h}$ 568 exposure to $0.05 \mathrm{mg} / \mathrm{mL}$ isoniazid (INH), $0.025 \mathrm{mg} / \mathrm{mL}$ rifabutin (RFB), 0.5 $569 \mathrm{mg} / \mathrm{mL}$ of unloaded LBG and LBG/INH/RFB (10/1/0.5, w/w) microparticles 570 (MP). Cells incubated with cell culture medium (CCM) are the negative control 571 and Triton-X 100 is the positive control. Data represent mean \pm SEM $(n=3$, six 572 replicates per experiment at each concentration). ${ }^{*} \mathrm{p}<0.05$ compared to $10 \%$ 573 Triton $\mathrm{X}-100$

574

575 A comparison of results obtained from the MTT and LDH assays shows that the 576 latter was more sensitive than the former. Drug-loaded LBG microparticles had 577 stronger impact in released LDH (Figure 5) compared with the effect on 578 mitochondrial dehydrogenase activity assessed in MTT assay (Figure 4B). Other 579 studies report similar observations (Braz et al., 2017; Wang et al., 2009) and 580 several justifications may apply. In fact, the two assays evaluate different aspects 581 of the interaction between cells and particles. A possible explanation is that 582 microparticles act as metabolic enhancers (Braz et al., 2017), thus accelerating MTT conversion into formazan in spite of the lower number of cells (as 
584

585

586

587

588

589

590

591

592

593

594

595

596

597

598

599

600

601

602

603

604

605

606

607

indicated by the LDH assay), resulting in the overestimation of cell viability. It may also happen that the interaction occurs mostly at the plasma membrane level, causing cell lysis but without reaching intracellular mitochondria (Wang et al., 2009). The latter is however possibly not applicable at least to THP-1 cells, given the phagocytic capacity of these cells.

The overall observation of cell viability results indicates that the formulation still needs some refinement to improve its toxicological profile. The results are no longer severe as those exhibited with higher amount of rifabutin (Alves et al., 2016), but there is still room for improvement, perhaps by working out a solution that eliminates the use of $\mathrm{HCl}$ in the preparation of microparticles. Additionally, the differences observed in the two assays reinforce the need to diversify the range of tests used to obtain a more realistic view of the true impact of the envisioned application.

\subsection{Uptake of LBG microparticles by macrophage-like cells}

Considering the aim of this work, it is very important to evaluate the ability of alveolar macrophages to uptake the produced microparticles. A preliminary study evidenced an uptake around 100\% of LBG microparticles independently of the tested dose (50 and $220 \mu \mathrm{g} / \mathrm{cm}^{2}$ ) and used cells (Alves et al., 2016). Considering this high affinity of LBG microparticles for macrophages, the lowest dose $\left(50 \mu \mathrm{g} / \mathrm{cm}^{2}\right)$ was selected to provide a comparison of behaviour between LBG and PVA microparticles. The latter were used as control because PVA is not reported to undergo specific recognition by macrophages. Moreover, in order to avoid interference of microparticle size in the uptake, PVA 
microparticles were tailored to have size similar to LBG microparticles (Feret's

609 diameter was calculated as $1.5 \pm 1.0 \mu \mathrm{m})$.

610 As depicted in Figure 6, very high macrophage uptake (95-100\%) was observed

611 for LBG microparticles in both cell lines. In turn, PVA microparticles induced

612 high uptake (92\%) in macrophage differentiated THP-1 cells, but this value

613 decreased significantly to $60 \%(\mathrm{p}<0.05)$ in rat alveolar macrophages (NR 8383

614 cells). In that case, the uptake was significantly lower than that induced by LBG

615 microparticles $(\mathrm{p}<0.05)$, showing a higher affinity of the cells for LBG.

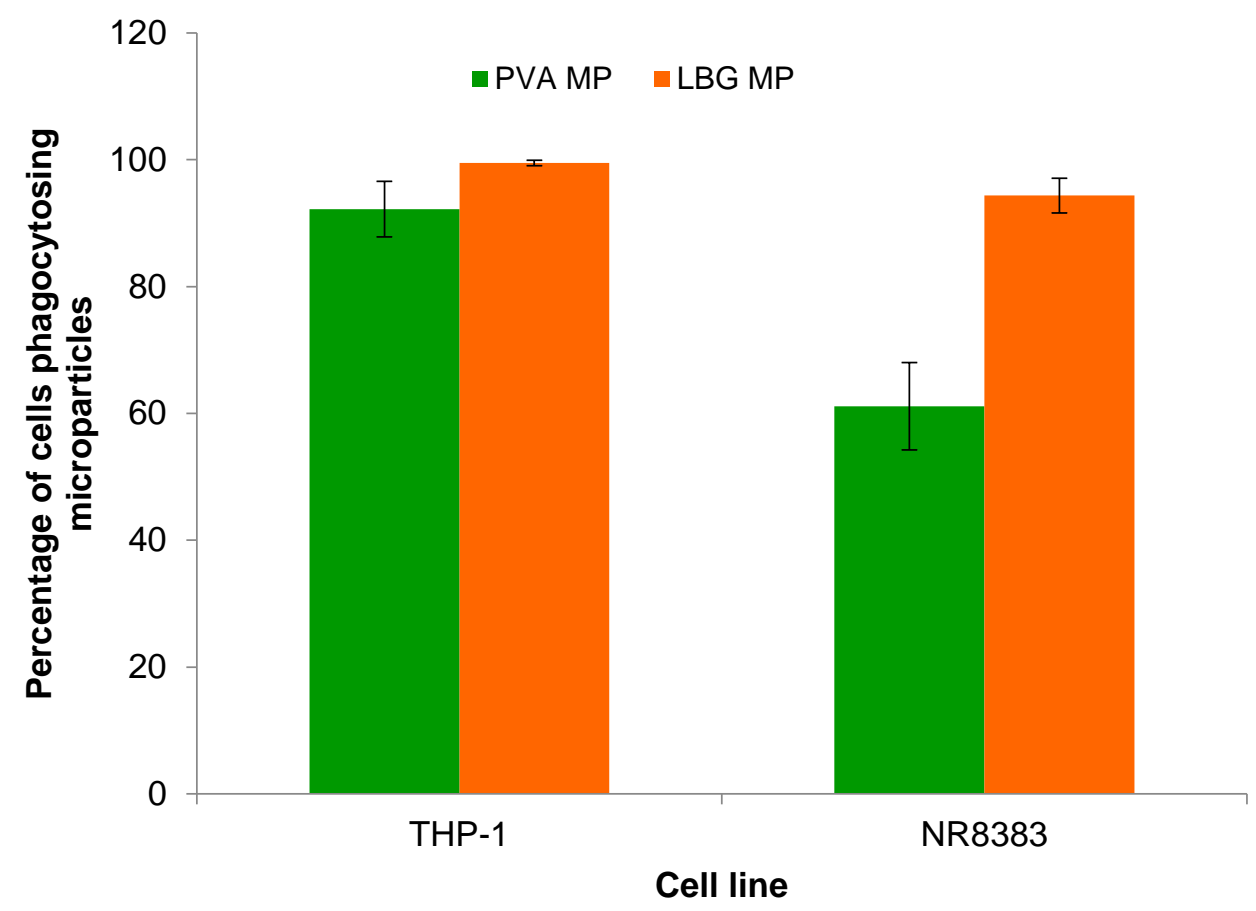

616

617 Figure 6. Uptake of fluorescently-labelled locust bean gum (LBG) and 618 polyvinyl alcohol (PVA) microparticles by macrophage-differentiated THP-1 619 cells and NR8383 cells upon $2 \mathrm{~h}$ exposure to $50 \mu \mathrm{g}$ microparticles $/ \mathrm{cm}^{2}$, at $37{ }^{\circ} \mathrm{C}$. 620 Results are expressed as mean $\pm \operatorname{SEM}(\mathrm{n} \geq 3)$.

622 Macrophages have a natural ability to uptake particulate matter (Pacheco et al., 623 2013; Patel et al., 2015) and, thus, the uptake of a certain amount of particles 
was expected in any case, independently of the particle composition. LBG is, however, a galactomannan, being composed of mannose and galactose units. These are reported to mediate favourable recognition by macrophage surface Ctype lectin receptors (Chavez-Santoscoy et al., 2012; Coombs et al., 2006; East and Isacke, 2002).

NR8383 cells are reported to naturally express a functional mannose receptor in culture (Vigerust et al., 2012). Therefore, the different response of these cells to the two formulations of microparticles is possibly due to a higher affinity for LBG, mediated by the specific receptor recognition of $\mathrm{LBG}$ residues. On the contrary, THP-1 cells differentiated by PMA adopt an activation state of M0 which has been reported to not express the mannose receptor (Daigneault et al., 2010). The inability to differentiate between both polymers is, therefore, the possible reason for the similar capture of the two microparticle types.

\section{Conclusions}

In this work, LBG microparticles loaded with a combination of the first-line antitubercular drugs isoniazid and rifabutin were proposed as inhalable carriers for tuberculosis therapy. The co-encapsulation of the drugs in a single carrier meets WHO requirements regarding combined tuberculosis therapy. Drug release from microparticles was fast, but this is expected to be counterbalanced by the reduced amount of fluid in the alveolar zone in in vivo conditions. The experimental assessment of aerosolisation properties of LBG microparticles demonstrated a favorable respirable dose lower than $5 \mu \mathrm{m}$, albeit the extrafine dose potentially capable of reaching the target alveolar zone should be enhanced in order to maximise macrophage uptake. A preferential ability of rat 

671 Controlled Release 79, 29-40.

672 Alkhayat, A.H., Kraemer, S.A., Leipprandt, J.R., Macek, M., Kleijer, W.J., 673 Friderici, K.H., 1998. Human $\beta$-mannosidase cDNA characterization and first

macrophages to uptake LBG microparticles in comparison with a control was observed in vitro, an effect attributed to the presence of mannose and galactose units in LBG. The cytotoxic evaluation of these microparticles demonstrated moderate decrease of cell viability to around $60 \%$, indicating the need to improve this aspect. Overall, the proposed strategy of dual antibiotherapy of tuberculosis mediated by inhalable LBG microparticles is believed to be a promising approach in the treatment of the disease.

\section{Acknowledgements}

This work was supported by National Portuguese funding through FCT Fundação para a Ciência e a Tecnologia, through projects PTDC/DTPFTO/0094/2012, UID/BIM/04773/2013, UID/Multi/04326/2013, UID/QUI/00100/2013, and PEst-OE/QUI/UI4023/2011. The studentship of Susana Rodrigues is also acknowledged (SFRH/BD/52426/2013).

The authors also would like to thank Plastiape Spa (Lecco, Italy) and Qualicaps (Madrid, Spain) for kindly donating the RS01 dry powder inhaler and HPMC capsules, respectively.

\section{References}

Ahsan, F., Rivas, I.P., Khan, M.A., Torres Suárez, A.I., 2002. Targeting to macrophages: role of physicochemical properties of particulate carriersliposomes and microspheres—on the phagocytosis by macrophages. Journal of 
674 identification of a mutation associated with human $\beta$-mannosidosis. Human 675 Molecular Genetics 7, 75-83.

676 Alves, A., Cavaco, J., Guerreiro, F., JLourenço, J., Rosa da Costa, A., Grenha, 677 A., 2016. Inhalable antitubercular therapy mediated by locust bean gum 678 microparticles Molecules 21, 1-22.

679 Belotti, S., Rossi, A., Colombo, P., Bettini, R., Rekkas, D., Politis, S., Colombo, G., Balducci, A.G., Buttini, F., 2015. Spray-dried amikacin sulphate powder for inhalation in cystic fibrosis patients: The role of ethanol in particle formation. European Journal of Pharmaceutics and Biopharmaceutics 93, 165-172. Braz, L., Grenha, A., Ferreira, D., Rosa da Costa, A.M., Gamazo, C., Sarmento, B., 2017. Chitosan/sulfated locust bean gum nanoparticles: In vitro and in vivo evaluation towards an application in oral immunization. Int J Biol Macromol 96, 786-797.

687

Bur, M., Huwer, H., Muys, L., Lehr, C.-M., 2010. Drug transport across pulmonary epithelial cell monolayers: Effects of particle size, apical liquid volume, and Deposition technique. Journal of Aerosol Medicine and Pulmonary Drug Delivery 23, 119-127.

691 Buttini, F., Colombo, G., Kwok, P.C.L., Wui, W.T., 2013. Aerodynamic Assessment for Inhalation Products: Fundamentals and Current Pharmacopoeial Methods, Inhalation Drug Delivery. John Wiley \& Sons, Ltd, pp. 91-119. Chavez-Santoscoy, A.V., Roychoudhury, R., Pohl, N.L.B., Wannemuehler, M.J., 695 Narasimhan, B., Ramer-Tait, A.E., 2012. Tailoring the immune response by 696 targeting C-type lectin receptors on alveolar macrophages using "pathogen-like" amphiphilic polyanhydride nanoparticles. Biomaterials 33, 4762-4772. 
698 Coombs, P., Taylor, M., Drickamer, K., 2006. Two categories of mammalian galactose-binding receptors distinguished by glycan array profiling.

700 Glycobiology 16, 1C-7C.

701 Daigneault, M., Preston, J., Marriott, H., Whyte, M., Dockrell, D., 2010. The 702 identification of markers of macrophage differentiation in PMA-stimulated 703 THP-1 cells and monocyte-derived macrophages. PLoS ONE 5, e8668.

704 Dalpiaz, A., Fogagnolo, M., Ferraro, L., Capuzzo, A., Pavan, B., Rassu, G., 705 Salis, A., Giunchedi, P., Gavini, E., 2015. Nasal chitosan microparticles target a zidovudine prodrug to brain HIV sanctuaries. Antiviral Research 123, 146-157.

707 East, L., Isacke, C.M., 2002. The mannose receptor family. Biochimica et 708 Biophysica Acta (BBA) - General Subjects 1572, 364-386.

EMA, 2014. Guideline on quality of oral modified release products. European 710 Medicines Agency, pp. 1-16.

711 Fröhlich, E., Mercuri, A., Wu, S., Salar-Behzadi, S., 2016. Measurements of 712 deposition, lung surface area and lung fluid for simulation of inhaled 713 compounds. Frontiers in Pharmacology 7, 181.

714 Grenha, A., Seijo, B., Remuñán-López, C., 2005. Microencapsulated chitosan 715 nanoparticles for lung protein delivery. European Journal of Pharmaceutical 716 Sciences 25, 427-437.

717 Gupta, A., Meena, J., Sharma, D., Gupta, P., Gupta, U.D., Kumar, S., Sharma, 718 S., Panda, A.K., Misra, A., 2016. Inhalable particles for "Pincer Therapeutics" 719 targeting nitazoxanide as bactericidal and host-directed agent to macrophages in 720 a mouse model of tuberculosis. Molecular Pharmaceutics 13, 3247-3255.

721 Haghi, M., Ong, H.X., Traini, D., Young, P., 2014. Across the pulmonary 722 epithelial barrier: Integration of physicochemical properties and human cell 
models to study pulmonary drug formulations. Pharmacology \& Therapeutics $144,235-252$.

Hiremath, P.S., Saha, R.N., 2008. Controlled release hydrophilic matrix tablet formulations of isoniazid: design and in vitro studies. AAPS PharmSciTech 9, $1171-1178$

ISO, 2009. Biological evaluation of medical devices Part 5: Tests for in vitro cytotoxicity, in: Standardization, I.O.f. (Ed.), 10993-5.

Kaur, M., Garg, T., Narang, R.K., 2016. A review of emerging trends in the treatment of tuberculosis. Artificial Cells, Nanomedicine, and Biotechnology 44, $478-484$.

Kyle, H., Ward, J., Widdicombe, J., 1990. Control of pH of airway surface liquid of the ferret trachea in vitro. Journal of Applied Physiology 68, 135-140.

Lankoff, A., Sandberg, W.J., Wegierek-Ciuk, A., Lisowska, H., Refsnes, M., Sartowska, B., Schwarze, P.E., Meczynska-Wielgosz, S., Wojewodzka, M., Kruszewski, M., 2012. The effect of agglomeration state of silver and titanium dioxide nanoparticles on cellular response of HepG2, A549 and THP-1 cells. Toxicology Letters 208, 197-213.

Lanone, S., Rogerieux, F., Geys, J., Dupont, A., Maillot-Marechal, E., Boczkowski, J., Lacroix, G., Hoet, P., 2009. Comparative toxicity of 24 manufactured nanoparticles in human alveolar epithelial and macrophage cell lines. Particle and Fibre Toxicology 6, 1-12.

Lee, W.-H., Loo, C.-Y., Traini, D., Young, P.M., 2015. Nano- and micro-based inhaled drug delivery systems for targeting alveolar macrophages. Expert Opinion on Drug Delivery 12, 1009-1026. 
747 Maretti, E., Rustichelli, C., Romagnoli, M., Balducci, A.G., Buttini, F., 748 Sacchetti, F., Leo, E., Iannuccelli, V., 2016. Solid lipid nanoparticle assemblies 749 (SLNas) for an anti-TB inhalation treatment: A Design of Experiments approach 750 to investigate the influence of pre-freezing conditions on the powder 751 respirability. International Journal of Pharmaceutics 511, 669-679.

752 Martinelli, F., Balducci, A.G., Rossi, A., Sonvico, F., Colombo, P., Buttini, F., 753 2015. "Pierce and inhale" design in capsule based dry powder inhalers: Effect of 754 capsule piercing and motion on aerodynamic performance of drugs. International 755 Journal of Pharmaceutics 487, 197-204.

756 McBryde, E.S., Meehan, M.T., Doan, T.N., Ragonnet, R., Marais, B.J., 757 Guernier, V., Trauer, J.M., 2017. The risk of global epidemic replacement with 758 drug resistant $M$. tuberculosis strains. International Journal of Infectious 759 Diseases 56, 14-20.

NICE, 2016. NICE guideline for tuberculosis, in: Excellence, N.I.f.H.a.C. (Ed.), 761 London.

762 O'Neil, M., 2006. The Merck Index: An encyclopedia of chemicals, drugs, and biologicals, 14 ed, New Jersey.

764 Pacheco, P., White, D., Sulchek, T., 2013. Effects of microparticle size and Fc 765 density on macrophage phagocytosis. PLoS ONE 8, e60989.

766 Pai, R.V., Jain, R.R., Bannalikar, A.S., Menon, M.D., 2015. Development and 767 evaluation of chitosan microparticles based dry powder inhalation formulations 768 of rifampicin and rifabutin. Journal of Aerosol Medicine and Pulmonary Drug 769 Delivery 29, 179-195. 

H.-K., 2016. Dry powder inhalable formulations for anti-tubercular therapy.

772

773

774

775

776

777

778
Advanced Drug Delivery Reviews 102, 83-101.

Patel, B., Gupta, N., Ahsan, F., 2015. Particle engineering to enhance or lessen particle uptake by alveolar macrophages and to influence the therapeutic outcome. European Journal of Pharmaceutics and Biopharmaceutics 89, 163174.

Peltonen, L., Valo, H., Kolakovic, R., Laaksonen, T., Hirvonen, J., 2010. Electrospraying, spray drying and related techniques for production and formulation of drug nanoparticles. Expert Opinion on Drug Delivery 7, 705-719. Ph.Eur., 2014. European Pharmacopoeia, in: Medicines, E.D.f.t.Q.o. (Ed.).

Pollard, M., Kelly, R., Fischer, P., Windhab, E., Eder, B., Amadò, R., 2008. Investigation of molecular weight distribution of LBG galactomannan for flours prepared from individual seeds, mixtures, and commercial samples. Food Hyd. 22, 1596-1606.

Rassu, G., Soddu, E., Cossu, M., Brundu, A., Cerri, G., Marchetti, N., Ferraro, L., Regan, R.F., Giunchedi, P., Gavini, E., Dalpiaz, A., 2015. Solid microparticles based on chitosan or methyl- $\beta$-cyclodextrin: A first formulative approach to increase the nose-to-brain transport of deferoxamine mesylate. Journal of Controlled Release 201, 68-77.

Singh, M., Bhatnagar, P., Mishra, S., Kumar, P., Shukla, Y., Gupta, K.C., 2015. PLGA-encapsulated tea polyphenols enhance the chemotherapeutic efficacy of cisplatin against human cancer cells and mice bearing Ehrlich ascites carcinoma. International Journal of Nanomedicine 10, 6789-6809. 
794 USP, 2015. United States Pharmacopeia USP-38, in: Convention, U.S.P. (Ed.),

795 Rockville.

796 Vigerust, D., Vick, S., Shepherd, V., 2012. Characterization of functional 797 mannose receptor in a continuous hybridoma cell line. BMC Immunology 13, 179813.

799 Wang, C., Muttil, P., Lu, D., Beltran-Torres, A., Garcia-Contreras, L., Hickey, 800 A., 2009. Screening for potential adjuvants administered by the pulmonary route 801 for tuberculosis vaccines. The AAPS Journal 11, 139-147.

802 Wells, B., Dipiro, J., Schwinghammer, T., Dipiro, C., 2009. Tuberculosis, 803 Pharmacotherapy Handbook, 9 ed. McGraw-Hill, p. 1066.

804 WHO, 2014. The End TB Strategy. World Health Organization, Geneva.

805 WHO, 2016 Global Tuberculosis Report 2016. World Health Organization, 806 Geneva.

807 